\title{
Por el Magdalena medio. Radios comunitarias para la paz, víctimas y reconciliación
}

In the middle of Magdalena. Community radiofor peace, victims and reconciliation

No meio Magdalena. Rádios comunitárias para paz, vítimas e reconciliação

César Augusto TAPIAS HERNÁNDEZ, Colombia

Universidad del Norte Colombia / ctapiasa@uninorte.edu.co

Chasqui. Revista Latinoamericana de Comunicación

N. ${ }^{\circ}$ 143, Abril-Julio 2020 (Sección Monográfico, pp. 161-180)

ISSN 1390-1079 / e-ISSN 1390-924X

Ecuador: CIESPAL

Recibido: 11-12-2019/Aprobado: 21-O3-202O 


\title{
Resumen
}

En este ensayo intento resolver las siguientes cuestiones ¿Cómo ha sido el desempeño de las radios comunitarias bajo el conflicto armado? ¿Qué experiencias tienen en torno a construcción de paz y convivencia? ¿Qué redes han tejido con la comunidad y las organizaciones sociales? ¿Qué enseñanzas hay para el sector de la radio comunitaria, la reconciliación y la curación posteriores al conflicto con las FARC_EP? Como estrategia metodológica, viajo por trochas y ríos buscando procesos comunicativos y apuestas de paz. Encontré que los procesos comunicativos para la transformación social siguen siendo la base de la comunicación popular comunitaria. Se concluye que el trabajo de estas radios en medio de la guerra ha dinamizado los imaginarios de una paz hecha desde las comunidades y sus organizaciones.

Palabras clave: construcción de paz, radio comunitaria, movilización, víctimas y reconciliación

\begin{abstract}
In this essay I try to solve the following questions: How has the performance of community radio stations under the armed conflict? What experiences do you have around building peace and coexistence? What networks have they woven with the community and social organizations? What lessons are there for the community radio sector, post-conflict reconciliation and healing with the FARC_EP? As a methodological strategy, I travel through trails and rivers looking for communication processes and peace bets. I found that communicative processes for social transformation continue to be the basis of popular community communication. It is concluded that the work of these radio stations in the midst of the war has energized the imaginary of a peace made from the communities and their organizations.
\end{abstract}

Keywords: peace building, community radio, mobilization, victims and reconciliation

\section{Resumo}

Neste ensaio procuro resolver as seguintes questões: Como tem sido o desempenho das rádios comunitárias durante o conflito armado? Que experiências você tem em torno da construção da paz e da coexistência? Que redes eles teceram com a comunidade e organizações sociais? Que lições existem para o setor de rádios comunitárias, reconciliação pós-conflito e cura com as FARC_EP? Como estratégia metodológica, viajo por trilhas e rios em busca de processos de comunicação e apostas de paz. Descobri que os processos comunicativos de transformação social continuam a ser a base da comunicação popular da comunidade. Conclui-se que o trabalho dessas rádios em meio à guerra vem dinamizando o imaginário de uma paz feita a partir das comunidades e de suas organizações. 
Palavras-chave: construção da paz, rádio comunitária, mobilização, vítimas e reconciliação

\section{Introducción}

Para llegar a San Vicente del Chucurí, debí tomar un autobús desde Barrancabermeja, una pequeña ciudad a orillas del río Magdalena, sede de la refinería de petróleo más grande del país y capital de la Provincia de Yariguíes ${ }^{1}$, como se llamaban los nativos de estas tierras, quienes desaparecieron por las enfermedades europeas, cuando no en las batallas que tersaban con los enloquecidos buscadores de 'el dorado' (Ferro, 2013; Gamboa, 2013).

La única vía pavimentada es la que te saca de la ciudad unos cuantos kilómetros hacia la serranía, el resto del camino es una carretera destapada, muestra paradójica del desarrollo en Colombia. La vía hacía uno de los puntos de mayor producción de cacao del país es un potrero. Sólo el Santander produce el $41 \%$ de todo el cacao que Colombia exporta (fedecacao, 2016). Pero la producción industrial del cacao y su transformación en el Chucurí es artesanal, si se tecnificara para producir derivados, mejoraría las condiciones económicas de los productores; pero ¿de qué manera entrarían los insumos? ¿a través de que vías transportar los productos finales? El mejoramiento de vías, una de las peticiones eternas de los movimientos sociales y campesinos (Archila, García, Parra, \& Restrepo, 2013, p. 589), permitiría a los agricultores acercar sus productos al mercado no sólo con fines de exportación; también para potenciar el comercio interno, y competir con los productos más baratos traídos de otros países.

Viajar desde Barrancabermeja hasta Simití, implicó tomar una lancha por el río Magdalena hasta el municipio de San Pablo, de ahí por tierra hacia Santa Rosa del Sur y después Simití, un pueblito colonial fundado el 1 de abril de 1537 por los españoles exploradores del Magdalena. Estos tres municipios junto con Norosí, Tiquisio, Arenal y Achí, conforman la subregión 'Sur de Bolívar' que, según el Monitoreo de cultivos de coca, hace parte de una región más amplia con Santander y Antioquia, que produce un $16 \%$ de la coca cultivada en el país (Unodc, ${ }^{2}$ 2014).

1 El departamento del Santander está conformado por provincias, figura administrativa apenas legalizada por el congreso de Colombia en 2017, aun cuando data de 1886 (Pinzón-Gonzales, 2007).

2 Sigla de Oficina de las Naciones Unidas contra la Droga y el Delito 
Fotografía 1. Réplica de un fruto de cacao, en el Parque central de San Vicente del Chucurí.

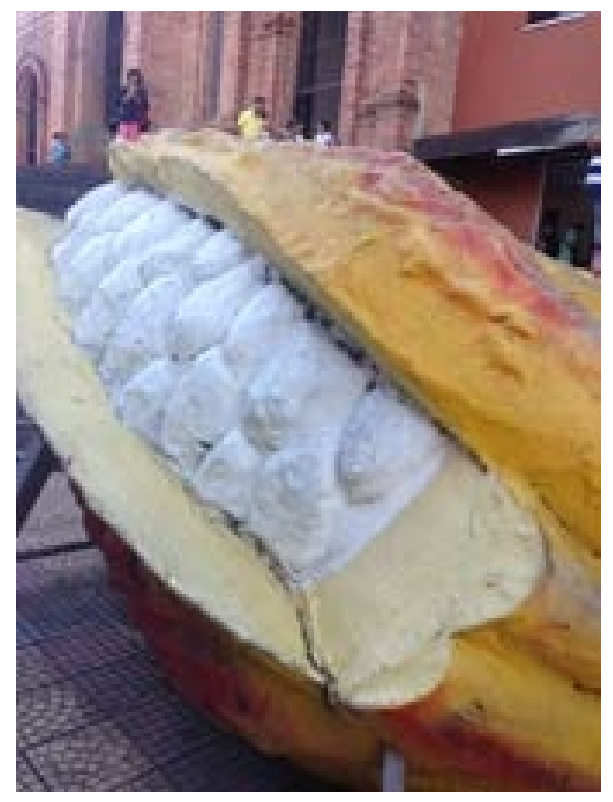

Fuente: Elaboración propia

Fotografía No.02 Puerto fluvial Yariguíes, Barrancabermeja.

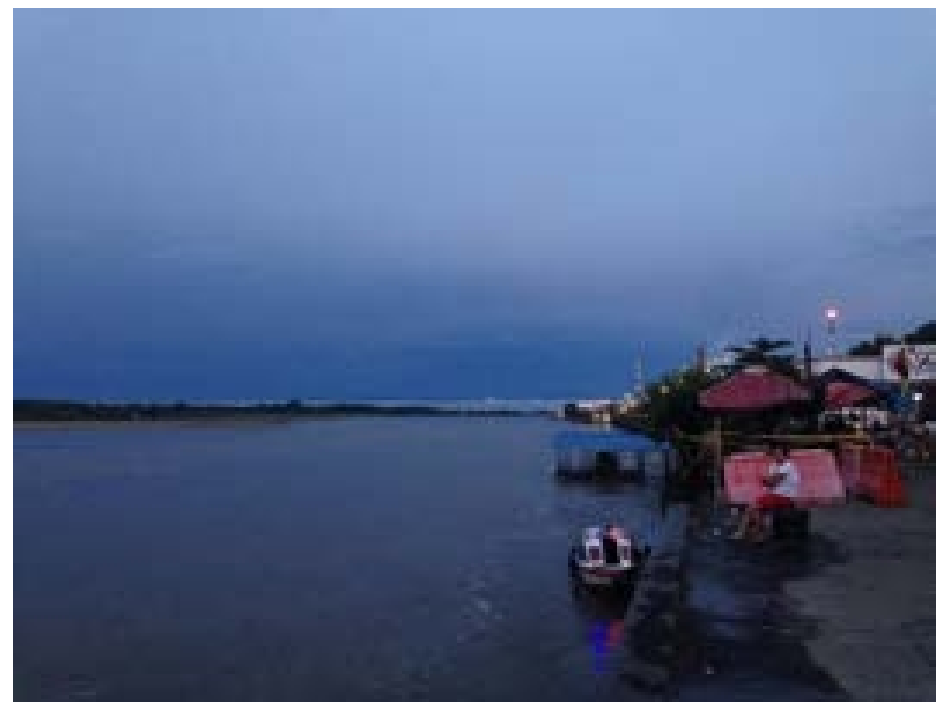

Fuente: Elaboración propia 
Para abordar, hay que ponerse un chaleco salvavidas, aunque... de caer, no sobrevivirías si tragaras estas aguas, aunque se ven aves y pescadores, es desesperanzador ver las salidas de alcantarillas, desde la propia planta de hidrocarburos hasta de los poblados que encuentras bajando por el río. El Magdalena atraviesa Colombia, recorre en su camino 125 municipios donde viven 6 millones de habitantes, un 13\% de la población nacional (Galvis-Aponte y Quintero-Fragozo, 2017). Otrora fue una importante vía fluvial; hoy, lleva nuestras porquerías hasta el mar: basuras, muertos, armas, drogas y corrupción, en vez de vida, o de los productos que miles de campesines que sólo la tienen fácil cuando siembran coca.

En Simití, conoceré la estación de radio comunitaria ‘Original estéreo', que debe su nombre a la Virgen de la Original, imagen hallada en la serranía de San Lucas a finales del S XVII y, asistiré a la reunión la Junta de Programación (en adelante JP) revitalizada por el proyecto de Radios Comunitarias para la paz y la convivencia (en adelante RCPC), del que hicieron parte entre 2015 y 2017. Aquí el trabajo de la radio está tan ligado a organizaciones sociales, que parece darle sentido a la hipótesis de que los Comités Temáticos Locales (En adelante CTL), habrían resuelto el problema en que se convirtieron las JP, ampliando la limitada la participación de audiencias (Vega, Pérez \&Tapias, 2019, p. 1403).

En San Vicente del Chucurí, me acercaré a la historia de Aredmag, la famosa red de radios comunitarias del Magdalena medio, creada en los 9o, como resultado de la experiencia de la unidad de comunicación del Programa de Desarrollo y Paz del Magdalena Medio (PDPMM), que fortaleció un proyecto de periodismo regional para construir dialógicamente las agendas locales de la región, y contrarrestar la estigmatización de la región en la prensa nacional (Cadavid, 2011, p. 73). También conversaré con representantes de organizaciones sociales que tienen espacios radiales en la emisora comunitaria San Vicente estéreo, fundada con apoyo de la iglesia católica pero donde también hay espacios para credos cristianos.

\section{Metodología}

En este ensayo intento resolver las siguientes cuestiones ¿Cómo ha sido el desempeño de estas radios bajo el conflicto armado? ¿Qué experiencias tienen en torno a construcción de paz y convivencia? ¿Qué redes han tejido con la comunidad y las organizaciones sociales? ¿Qué enseñanzas hay para el sector de la radio comunitaria, la reconciliación y la curación posteriores al conflicto? Será preciso tratar de construir mi objeto en términos del movimiento, ya que viajo para conocer diferentes procesos comunicativos y sus formas de construir la paz, por las trochas del Chucurí, por el sucio río Magdalena.

Con la Junta de Programación de Simití Original estéreo, conversamos en la calle adjunta a la casa de su director, mientras que con Edgar el coordinador de la experiencia de Simití en RCPC, entre cervezas y risotadas en una taberna; con 
Orley líder de Aredmag, logré un intercambio de saberes, él me compartió sus impresiones sobre radio comunitaria y cambio social, y yo le compartí maneras dinámicas de hacer una entrevista. Con el colectivo de producción local de San Vicente, conversamos a partir de unos dibujos que hicieron sobre una anécdota en la emisora. Se necesitan formas innovadoras de etnografía multilocal para investigar viajando, así fue que Leonardo me contó cómo se jalonó el paro agrario de 2013. Quizás la entrevista más sensata para comprender el grado de articulación de la emisora con la comunidad fue con los miembros de Asojuntas ${ }^{3}$, en particular con su presidente quien, mientras dibujaba una ventana, me contabas pormenores de su labor en la emisora y como a veces desconoce el manual de estilo y entra en confrontaciones. A los Radialistas del Comité de consulta anti minera los visité en una de sus fincas... así, conversando fue que obtuve pruebas etnográficas suficientes para valorar cómo la comunidad se integra a la radio para intentar superar los malos tiempos construyendo unos mejores.

\section{Desarrollo}

Fue en el gobierno de Ernesto Samper (1994/1998) que se aprobó el Decreto 1447 de 1995 que reglamentaba las emisoras comunitarias en Colombia. Estas radios, en general, han sido fundadas por asociaciones $u$ organizaciones de comunicación, comunales, étnicas, religiosas, ambientales, entre otras. Cualquiera sea su origen, por ley, estas radios deben estar comprometidas con la participación y el pluralismo entre los habitantes, deben promover el dialogo público, desarrollar temas que tengan que ver con el desarrollo y la convivencia, la paz, el respeto y el desarrollo de la cultura (Fajardo, Toloza, Tibaduiza \& Marín. 2010). Para ello se reglamentaron las JP y los CTL (Vega, Pérez \&Tapias, 2019).

En 2004, casi diez años después, la Unidad de Radio detecta entre las radios locales una gran urgencia por producir programas de información. Así que, con fondos de varias agencias internacionales, implementó un proyecto de acompañamiento a 40 emisoras comunitarias y un tanto más de Colectivos de comunicación ${ }^{4}$ (González y Rodríguez, 2006). Se funda el Programa 'Radios Ciudadanas' (RC) que irá hasta 2010, cuando se vuelve estrategia transversal de todos los programas de radio comunitaria apalancados desde el Ministerio de Cultura.

Pero 'RC' tuvo un complemento importantísimo para la construcción de la paz, y la transformación de las radios comunitarias en radios ciudadanas. Se trata de 'Radio, un lugar para la diferencia' (RLPD), programa desarrollado entre 2004 y 2006, con la Oficina del Alto Comisionado para la Paz (OACP), en regiones como el Caguán (Caquetá) y la Macarena (Meta), que habían sido

3 Asociación que integra a todas las de Juntas de Acción Comunal del municipio de San Vicente

4 EN RCPC se conocerán como Colectivos de producción local (CPL) 
epicentro de 'Los diálogos del Caguán' entre el gobierno de Andrés Pastrana y las FARC-EP entre 1998 y 2002. 'RLPD' fue la pista de despegue para consolidar una dimensión central de la radio local en contextos de violencia: lograr procesos de participación donde más que el volumen de producción lo que importe, sea que muchos ciudadanos cuentan su diversidad (MinCultura, 2010).

En el marco de las negociaciones de paz en La Habana entre el Gobierno colombiano de Juan Manuel Santos y la guerrilla de las FARC_EP, en el año 2014, OACP, Presidencia de la República, los Ministerios de las TIC, y de Cultura, y la Unión Europea (UE), concertaron la realización del proyecto 'RCPC' bajo operación de la red cooperativa de emisoras comunitarias de Santander (Redsander), entre 2015 y 2017. Su objetivo era contribuir a la construcción de una cultura de paz y convivencia a nivel territorial, y para conseguirlo, acompañaron 50 emisoras comunitarias de distintas regiones de Colombia, entre ellas, La Original estéreo de Simití, para fortalecer el abordaje de temas como reconciliación, convivencia y paz a través de procesos de formación, producción radial, y la posterior circulación a nivel nacional de los contenidos producidos, que vincularía a otras 400 radios locales, como San Vicente estéreo. Sin embargo, a pesar de este volumen de radios involucradas, finalizada la segunda década del S XXI, en la mitad de los municipios del país no existen medios de comunicación que produzcan información local y no se cuenta con canales comunicativos para garantizar la participación ciudadana en temas de interés general (Flip, 2019). Tal vez la convocatoria para otorgar nuevas licencias de radiodifusión comunitaria al cierre del año 2019, cubra parte del saldo.

En 2001, el apogeo de las emisoras en cientos de municipios del país hizo que se formalizaran las redes de radio comunitarias, unas asociaciones a nivel departamental, regionaly nacional, formadas por organizaciones concesionarias para difundir de manera ocasional o permanente, en forma simultánea o por el sistema de pregrabados, la programación de las emisoras en-red-adas, y para coordinar su trabajo y gestión ante las entidades públicas y privadas (Art 11. Cap. III Proyecto de ley 83 de 2012). En la actualidad existen 29, una de ellas es 'Aredmag', la asociación de radios comunitarias del Magdalena Medio, que ha sido la más mítica de todas las redes por sus estrategias de comunicación para el cambio social, dentro de las que se destaca la generación de opiniones públicas favorables a la paz.

Pero las redes más exitosas son la que se logran tejer con las organizaciones presentes en los territorios. Así es como 'Aredmag' consolida con informadores campesinos una articulación con otros procesos sociales de la región como los 'Núcleos de pobladores' del PDPMM, las juntas de acción comunal y las asociaciones de pescadores y de mujeres, entre otros. 
En la región del Magdalena Medio, los procesos de apropiación de lo público no se dan sólo en las radios locales; sino en procesos mucho más amplios, de movimientos sociales y políticos de recuperación de la democracia para el territorio. Y aun en el caso de los medios comunitarios, no se trató de uno o dos de ellos, ni se destacaron una o dos personas; allí son 17 medios y las personas que lideran estos procesos se ubican en varios ámbitos de las organizaciones locales o de la red misma, desde los directivos de la asociación, hasta los colectivos de jóvenes, mujeres y campesinos que se apropian del discurso sobre la necesidad de construir y aportar a lo público, y lo traducen de diferentes formas e historias en sus medios locales.(El'Gazi, 2011, p. 304)

Aredmag se hizo una telaraña de 17 emisoras comunitarias, 22 colectivos de comunicación, 7 radios escolares y varios grupos de personas afines a un proyecto político y de comunicación que cubrían temas como la salud sexual y reproductiva, derechos de la infancia y la adolescencia, la equidad de género, entre otros a través de programas de opinión en el marco del proyecto 'RC', lo que significó para la región, nuevas formas de acceso a la producción de contenidos, y la participación de los diferentes grupos sociales (Durán, 2011).

Estos Colectivos, junto con el programa 'Reporteros rurales' constituyen los primeros espacios sociales para la participación de las audiencias en la radio comunitaria. El trabajo en red propició un enlace regional, por medio de un magazín informativo denominado 'Tejiendo la Red', donde reporteros rurales divulgaban aspectos relevantes de diversas poblaciones. Además, editan el periódico 'La Telaraña', para el cubrimiento de informaciones de índole regional y, a su vez, el abordaje de temas organizacionales de la agremiación (Gómez Ditta, 2011, p. 335).

Cuando llegó el proyecto de 'Radio Ciudadanas', ellos nos decían, que a las seis de la mañana sabían lo que pasaba en el mundo, en el país entero; pero desconocían lo que ocurría en su pueblo, de ahí nace la idea de un informativo local, y surge la reportería rural, un proyecto único en el sentido que eso se montó hace 22 años; pero es como si se hubiera montado para estos momentos, para el proceso de paz. (Leonardo Amaya, Entrevista personal No. 1 septiembre de 2018)

En este sentido, hay pruebas de cómo las emisoras del Magdalena medio abrieron espacios de diálogo al interior de las comunidades donde los actores en conflicto pudieron dirimir sus diferencias y considerar diferentes propuestas de conciliación. Y es que en algunos entornos de conflicto, los periodistas ven su papel como más complejo que ser simplemente portadores de información, y buscan activamente facilitar los diálogos más importantes de consolidación de la paz necesarios en sus comunidades (Howard, 2002). Sin embargo, la mediación de la emisora no es suficiente para resolver el conflicto, las autoridades locales tienen que intervenir en la resolución. Así, las emisoras del Magdalena medio se fueron convirtiendo también en dinamizadoras de procesos en los cuales las 
autoridades locales se vieron presionadas a asumir su responsabilidad de velar por el bien común (Rodríguez, Cadavid \& Durán. 2008, p. 163)

Con todo y la vanguardia que representó en el periodismo regional, Aredmag también tuvo dificultades con radios comunitarias aisladas no sólo del movimiento regional de radios, sino y más grave, de las realidades locales de sus propios municipios. Y 25 años después entra en un declive sociopolítico a razón de los contratos con los que empieza a obtener mayores recursos económicos. Comenzar a pagar por hacer lo que se venía haciendo por convicción, rompió la confianza, los afectos, la credibilidad y en general, los eslabones de la red de radios, de organizaciones, de gentes. Los patrones neoliberales de la acumulación y reproducción de capital hicieron de una relación colaborativa; una contractual, que bloqueó el trabajo del cuidado, el trabajo emocional, las conexiones entre las personas (O’Brien, 2018, p 679)

El goce se perdió por el afán de los recursos, y se convirtió en una pesadilla, fue así como por 8 años, mientras más recursos entraban, mayores eran los problemas de legitimidad, y la junta directiva de Aredmag se creyó el cuento de que no era la red la que respondía a las emisoras, sino las emisoras las que les respondían a Aredmag, lo que desnaturalizó la creación de lo que pensábamos que era la red. (Orley Durán, Entrevista personal No. 2 septiembre de 2018)

En la actualidad, el único trabajo de producción y emisión conjunta es una Serie de programas llamada "En comunidad" que el colectivo de San Vicente estéreo edita con materiales producidos por cada una de las emisoras "contratadas",

Actualmente tenemos 16 emisoras afiliadas, 6 aliadas y una emisora pirata que es reconocida en su pueblo, la de 'Canta gallo'. Con ellas venimos desde hace aproximadamente dos o tres años haciendo proyectos para ISAGEN, proyectos para repartir inicialmente entre las emisoras afiliadas a la red, pero ahora los estamos haciendo a nivel nacional con emisoras de los departamentos de Antioquía y Caldas, unas 25 o 30 emisoras en todo el país y con otras redes, como la asociación de redes de Antioquía (ASOREDES) y algunas emisoras independientes con las que tenemos un contrato. (Sonia Durán, Entrevista personal No. 3, septiembre de 2018)

Igualmente, las radios de Aredmag transmitieron 'Así suena la paz en los territorios' el programa de difusión por 400 emisoras comunitarias, de los productos de RCPC, coordinado como ya dijimos, por 'Redsander', la red que ha venido ocupando el espacio que dejó Aredmag, actuando de manera eficiente, legitimando el trabajo de las redes en el país y de la mayor cantidad posible de radios comunitarias,

...el reto es que 'Aredmag' vuelva ser un referente nacional en ese sentido, y que se convierta en un interlocutor clave a nivel regional de esos procesos e iniciativas de desarrollo social, de derechos humanos en la región, y coyunturas nacionales como 
el tema de La Paz, o lo que pasa ahora con la $\mathrm{JEP}^{5}$ o con la Comisión de la Verdad ${ }^{6}$. (Orley Durán, Entrevista personal, No. 2 septiembre de 2018)

En 2013, el Grupo de Memoria Histórica identificó cuatro periodos en el desarrollo de violencia en el Magdalena medio, lo que muestra que la violencia política, por ejemplo, es un proceso histórico que no deja de evolucionar,

1. (1958-1982) transición de la violencia bipartidista a la violencia subversiva que contrasta con el auge de la movilización social y la marginalidad del conflicto armado.

2. (1982-1996) crecimiento militar de las guerrillas, surgimiento de los grupos paramilitares, crisis y el colapso parcial del Estado, irrupción y propagación del narcotráfico.

3. (1996-2005) recrudecimiento del conflicto armado por las expansiones simultáneas de las guerrillas y de los grupos paramilitares, la crisis y la recomposición del Estado.

4. (2005-2012) reacomodo del conflicto armado por ofensiva militar del Estado, debilitando, pero no doblegando la guerrilla, que se reacomodó militarmente.

Podemos agregar un quinto periodo, que sería la violencia del post acuerdo (2016/ 202?). Tras la dejación de armas por parte de las FARC_EP, hay un reacomodo de otras fuerzas que incluyen redes de narcotráfico transnacional, en espacios dejados por la guerrilla y que no ocupó el estado, visibilizando/ vulnerando la seguridad las comunidades marginalizadas, sus organizaciones, líderes, lideresas y exguerrilleres firmantes de la paz. En toda la región se viven las violencias del post acuerdo actual, con el recuerdo vivo de la avanzada paramilitar (1996-2005), que Simití sólo pudo superar con una fuerza creativa que canalizaron diversas organizaciones sociales y culturales convocando al retorno; en San Vicente del Chucurí devino en una pacificación violenta, silenciosa y sin garantías de no repetición; pero en San Pablo (por donde descendí de la lancha que me trajo desde Barranca por el rio...), la violencia paramilitar silenció la iniciativa de comunicación comunitaria de Adecosan (Ver Granada, Restrepo \& Sánchez, 2014, p. 49).

Una de las preguntas que formulé a mis interlocutores, fue ¿Cuál ha sido el rol de las radios comunitarias en estos contextos del país donde a la gente le están cobrando el pecado de desear/hacer la paz?

¡Mire los resultados que obtuvimos este pasado domingo en la consulta anticorrupción 7 !, ¿cómo es que en ciertas regiones del país no salieron a

5 Sigla para el Sistema de Justicia especial para la paz, creado por el proceso de paz

6 Instancia creada en el proceso de paz con las FARC para recoger las verdades de la guerra

7 Consulta popular del 26 de agosto de 2018 , que buscaba respaldo electoral para endurecer las sanciones 
votar? Quedamos a medio millón de votos del éxito, y no es porque el pueblo no quiera rechazar la corrupción, lo que pasa es que se encuentra con una opresión armada que, si salen, se mueren... Y la vida es más valiosa que un voto. (Huber Izaquita, Entrevista personal No 4, septiembre de 2018)

En el post acuerdo, como en los momentos más sangrientos de la violencia histórica, los movimientos sociales requieren mantener a sus integrantes comunicados, ampliar su base social, ganar visibilidad y reconocimiento, por lo que son necesarias algunas estrategias de comunicación. Gabriel Kaplún (2007, p. 315) dice que la comunicación popular comunitaria, debe estar en favor de los intereses de los sectores populares, estableciendo vínculos con organizaciones representativas de la diversidad social. Y llama la atención sobre medios populares y comunitarios que no han estado en sintonía con los movimientos y organizaciones sociales. No ha sido el caso de las radios del Magdalena medio. Allí, poder encontrarse con la comunidad, con las organizaciones y sus realidades para hacer radio, les ha permitido a unos y otros, resolver juntos cómo mostrar, contar e incluir sus voces para movilizar, visibilizar, empoderar y transformar lo social.

Foto 3. En cabina sonora de Simití Original estéreo con los locutores Fidel (atrás), Eliecer (Izquierda) y Edison (derecha)

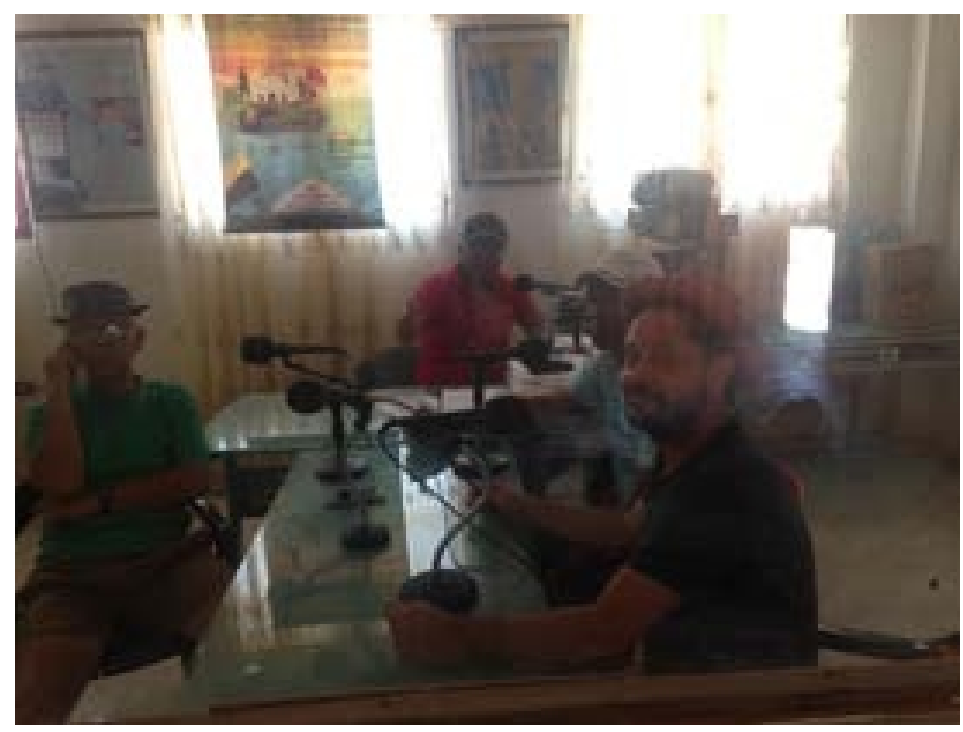

Fuente: Elaboración Simiteña

contra los corruptos en Colombia y que no consiguió superar el umbral de más de 12 millones de votantes (el 33\% del censo) que necesitaba para ser aprobada. Ver https://elpais.com/internacional/2018/08/26/ colombia/1535315276_191058.html 
Se puede tomar como ejemplo reciente, el Paro Nacional Agrario del año 2013, famoso por la frase del presidente Santos "el tal paro agrario no existe" (El Espectador, septiembre 20 de 2013) ${ }^{8}$. La movilización cacaotera del Chucurí que fortaleció ese Paro, emergió desde finales de 2011 en un programa que tenía la emisora comunitaria San Vicente estéreo, bajo el nombre "el cacao está en la olleta”, que en realidad lo está(ba) por el aumento de las importaciones del cacao en grano y subproductos como la cocoa con cero aranceles, el contrabando, el alto costo de los insumos, la imposibilidad de atender las deudas con el sector financiero, el precio bajo de compra del grano de cacao y por el manejo inadecuado por parte de Fedecacao de los aportes parafiscales (Mesa Nacional Cacaotera, 2013, p. 54).

Fotografía N4 Del Story board de Leonardo Amaya

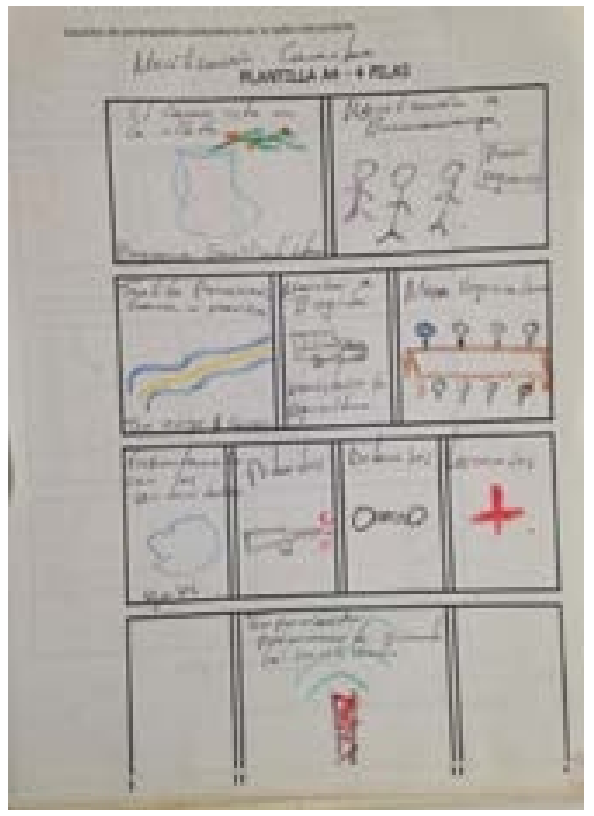

Fuente: Elaboración propia, al ejercicio creativo en la entrevista colectiva a miembros del Colectivo de Comunicación de San Vicente estéreo

Con los 78 programas que hicimos, fui varias veces con la movilización hasta Bucaramanga, a la vía Panamericana, hasta el ministerio en Bogotá, hasta en la mesa negociadora, aparte de eso, narré el enfrentamiento de las comunidades con las autoridades, los gases lacrimógenos, los petardos, los detenidos, las personas

8 Más información: https://www.elespectador.com/noticias/politica/presidente-admitio-embarro-al-decir-el-tal-paro-agrario-articulo-447581 
heridas... hubo quienes me manifestaron que me convertí en un reportero de guerra. (Leonardo Amaya, Entrevista colectiva No.1 septiembre de 2018)

Aquí vemos cómo la radio comunitaria, junto con las organizaciones sociales, hace el giro metodológico y de acuerdo con el discurso de la profesora Clemencia Rodríguez (2011) se transforma en una radio ciudadana, una radio que más allá de la función social básica de informar y ayudar a la gente que necesita con los anuncios sociales; potencia una articulación con las organizaciones, buscando que los actores comunitarios se apropien del ejercicio público en la radio y se conviertan en ciudadanos que participan de la vía pública. Es el caso de la relación entre San Vicente estéreo y el Comité promotor de una consulta popular que desde 2016 se opone a la explotación minera en el Chucurí, "Tenemos un programa donde promovemos la consulta popular, informamos a los chucureños del proceso y motivamos su participación, y somos tendenciosos, porque queremos que la comunidad diga no a la minería" (Edwin Silva y Norberto Carreño, Entrevista colectiva No. 2, septiembre de 2018).

En Simití Original estéreo, la catarsis o el despertar de la pesadilla de la guerra y la construcción de la paz, se potenció con una radio que también fue víctima de la confrontación armada; pero que capitalizó su retorno, tejiendo como en los años mozos de aredmag, redes con la comunidad, principalmente con la más afectada,

(...) por el Cerro de Burgos, que es la entrada de Simití desde el río Magdalena, fue por donde entraron los paramilitares al Sur de Bolívar. Ahí fue el primer desplazamiento masivo de simiteños... eso todavía se ve en el rostro de la gente. En nuestro proyecto radial tuvimos como participantes a la Mesa de Víctimas de ese corregimiento, porque era importante el tema de recuperación emocional, poder contar lo que había pasado, para recuperarnos un poquito emocionalmente después que fuimos arrasados por los violentos. (Edgar Arrieta, Entrevista personal No. 5, Septiembre de 2018)

La radio comunitaria de Simití tiene tres momentos en su historia: el antes, que es cuando la Corporación Laboral Educativa Básica de Especialización Regional (Cleber) ${ }^{9}-$, la crea con ayuda directa del gobierno nacional que la entrega sin licitación alguna; el durante, que fue bajo el tercer periodo -ya reseñado- del conflicto armado, cuando el edificio Cleber, centro de enseñanza, comunicación y encuentro social del pueblo, construido comunitariamente, fue ocupado por los paramilitares, lo que les significó el cierre de la emisora y el desplazamiento forzado de sus líderes y lideresas; y el después, o el posconflicto con los paramilitares "desmovilizados" en 2006, fechas desde cuando la emisora asume el compromiso cívico de potenciar al desarrollo de Simití.

9 Ver, clebersimiti.org 
El primer escenario para este propósito, fue en 2006 con el programa 'RC', donde a partir de la interacción entre la emisora y la comunidad en el marco del trabajo con Aredmag, surgió el Colectivo Comunicaciones 'Sombreros, Pescado y Tambó', un proceso de comunicación con niños y niñas que aún después de 14 años continúa desarrollándose bajo el liderazgo la docente Sofía Torrenegra, quien emplea la comunicación como forma de ejercer la pedagogía entre sus estudiantes y los ciudadanos del entorno al colegio (Gómez Ditta, 2011); "de este colectivo salieron varios jóvenes quienes obtuvieron becas para estudiar comunicación social en la Universidad Minuto de Dios, y hoy son unos profesionales" (Jaime López, Entrevista colectiva No. 3, septiembre de 2018).

El segundo escenario fue RCPC, donde cada emisora debió cerrar su participación con un 'Evento público', como se denominaron los espacios sociales que dinamizaron la interacción entre las radios comunitarias y sus comunidades, en un nivel de diálogo más amplio sobre la construcción de paz y la convivencia, que las radios desarrollaron bajo varias modalidades: Foro ciudadano, Encuentro cultural, Cine foro, Conversatorio ciudadano, Senderos ecológicos, etc. El de Simití fue un encuentro cultural que logró visibilizar y rescatar la memoria histórica como estrategia para proponer el renacer de la cultura simiteña. Al evento, desarrollado en septiembre de 2017, se vincularon más de 15 organizaciones sociales, culturales y hasta comerciales, llegaron más de 400 personas, e hicieron presencia como invitados una docena de periodistas internacionales y representantes de las entidades financiadoras del proyecto como la Presidencia de la República y la Unión Europea,

Lo que hicimos fue pensarnos el posconflicto con la ayuda de los colectivos culturales, y construir resiliencia. Esto es, sanarnos a través de la cultura. Recordar, vivir, pero también sanarnos mientras contamos los cuentos, hacemos los bailes, recuperamos las tradiciones, todo lo que había antes de la violencia. Porque la cultura, emocionalmente, es lo que lo puede sacarnos adelante. (Edgar Arrieta, Entrevista personal No. 5, septiembre de 2018)

Pero este nivel de diálogo fue exitoso gracias al trabajo logrado con el CTL, la estrategia de socialización mejor valorada de RCPC, que fortaleció la emisora comunitaria en cuanto a procesos de planeación y producción, y más importante, de participación ciudadana, dinamizando y ampliando las posibilidades de la construcción social de la radio, de sus contenidos mediáticos y de ambientes sociales saludables. Como circunstancia estructural para el caso de Simití, su CTL realizó talleres de meditación, como preámbulos a los encuentros donde los participantes planeaban sus programas y diseñaron el evento público. 
Fotografía 5 Ciénaga de Simití, casas bordeándola y en primer plano 'La Simiteña'

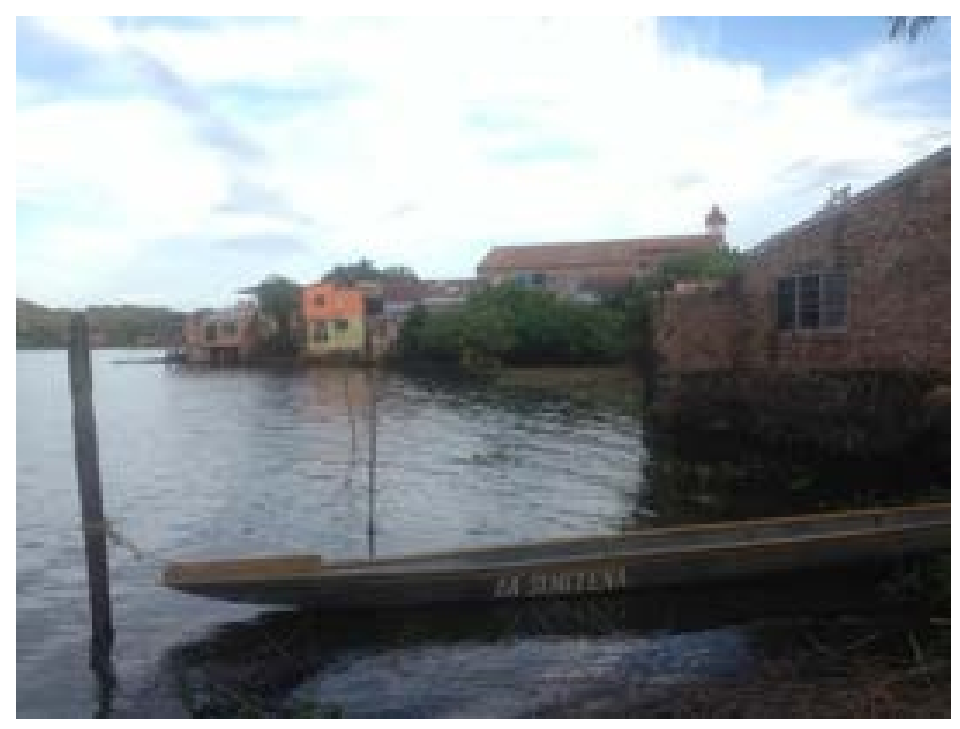

Fuente: Elaboración propia

Caminando por el borde la Ciénaga, imaginándola hace casi 500 años con los indígenas diezmados por los españoles, y a los campesinos, siglos después reducidos por los diferentes ejércitos en su avanzada de colonización interna, pienso con más certeza en realizar una intervención, para observar de manera directa el efecto de los medios locales en el post acuerdo y sus posibilidades para la sanación, o la reconciliación. Creo que sería clave en mi disertación doctoral sobre radios comunitarias y construcción de paz, involucrar como en Simití además de la meditación, la diversidad comunitaria expresada en múltiples organizaciones que se encuentran para escucharse y conectar con el resto de seres humanos. Debido a la escasez de servicios de salud mental en medio de la violencia armada (Jiménes-Jiménes, 2009, p. 14), los medios comunitarios serían determinantes en estos entornos (Wolfsfeld, 2004, p.86) con apuestas pedagógicas por la palabra.

La experiencia de San Vicente estéreo en su interacción con organizaciones sociales, incluso otras iglesias, permite ver que la organización concesionaria de la radio comunitaria debe estar estructurada desde lo administrativo, social y cultural. Esto incluye procesos contables, reglamentos y manuales, y que cada área de la emisora tenga funciones y propósitos claros; que la estructura organizativa permita promover, construir y fortalecer el proyecto comunitario (Fajardo et al. 2010). Esto porque, 
Hay emisoras que se personalizan, que son manejadas por la parroquia, o por los sacerdotes, quienes las toman únicamente para su comunidad, y la llaman comunitaria, porque llevan allá sus comunidades a que participen y hagan radio, pero lo que ocurre en San Vicente Estéreo es diferente, porque acá sí tienen participación los diferentes credos religiosos, filosóficos, políticos, claro, en cumplimiento del manual de (estilo) ética que tiene la emisora, para prestar servicio a la comunidad sin dejar de ser cuidadosos del tipo de información que se vaya a transmitir. (Isidoro Caballero Arenas, Entrevista personal No 6, septiembre de 2018)

Del mismo modo, las emisoras comunitarias podrían formular políticas internas específicas sobre el contenido dirigido a los niños, o que represente a las mujeres, o sobre tipos de publicidad permitidos, o sobre asuntos que afecten la salud, o que faciliten la toma de decisiones colectivas sobre esos asuntos. Estas radios deberían establecer un sistema para garantizar que su personal y voluntarios conozcan todos los códigos y requisitos legales que deben respetarse dentro de la estación (Kanchan, 2015, p.759).

El programa radial de Asojuntas inicialmente tenía media hora; ahora está ocupando una hora completa, a veces un poquito más, y eso ha chocado con las directivas de la emisora, porque como ellos manejan una parrilla de programación, un contenido específico, en cambio lo mío es más imprevisto, es más de lo que está pasando en el momento y que yo no puedo dejar para desarrollarlo después, entonces o me puedo demorar 20 minutos, o me puedo demorar dos horas. (Huber Izaquita, Entrevista personal No 4, septiembre de 2018)

Sin embargo, a pesar de reglamentaciones como el decreto 1981 de 2003 , que establece en su parágrafo 30 que dentro de los seis (6) meses siguientes al otorgamiento de la licencia, los concesionarios del servicio comunitario de radiodifusión sonora deberán elaborar y dar a conocer a la comunidad el manual de estilo, hay emisoras que no cuentan con este instrumento de mediación y gestión; allí, desde la dirección solo se dan instrucciones acerca de los enfoques y temas que se deben tratar, otras por lo menos tienen en cuenta las pautas dadas por Sayco y Acimpro para la emisión de piezas musicales, por ejemplo, sobre cuántas veces debe sonar una canción. Por sobre todo eso, está la normatividad estatal que prohíbe el proselitismo político (García y Orrego, 2017, p.44), y aún así, hará falta más que el manual como un texto, el escenario de concertación y construcción colectiva de los deberes de la radio y las organizaciones o personas participantes.

\section{Resultados}

En este viaje encontré experiencias de comunicación comprometidas con el cambio social, desde la imagen de una región completa como fue el trabajo 
de los reporteros rurales en oposición a los estereotipos de la comunicación masiva, hasta procesos de sujetos individuales y colectivos que también se transformaron, como los estudiantes participantes del colectivo de Simití, becados por Uniminuto. Sin embargo, no puede decirse que estos resultados sean inesperados, ya que hay una evidencia empírica acumulada en los trabajos de Rodríguez, Cadavid y Durán (2008), Gómez Ditta; Durán (2011), y en Vega, et al. (2019), sobre por ejemplo, la capacidad de mediar conflictos, de movilizar comunidades y moderar debates públicos no sólo de las radios en-red-adas en aredmag, sino también con redsander.

Los resultados también confirman que si la guerra no se detiene, las acciones comunicativas de civiles organizados tampoco, 10 años después de 'RC' y otros 3 después de RCPC, encontramos radios fortalecidas en sus alianzas con organizaciones sociales: en el caso de Simití Original estéreo, posterior a 2017, ha ejecutado proyectos ambientales desde la perspectiva comunicativa, con colectivos culturales preocupados por la ciénaga y el río. Por su parte, San Vicente estéreo, está diseñando una serie radial sobre la convivencia entre exparamilitares y la comunidad chucureña. Esto significa que la estructura social comunitaria confiere un rol determinante de la comunicación y la organización comunitarias, para afrontar dificultades locales.

Entre los hallazgos más importantes, destaco que en San Vicente estéreo brinde muestras de disenso o desencuentros que no afectan los procesos comunicativos, sino que hacen verlos como tensiones que intentan equilibrarse, cuando no se cumple el manual de estilo, por ejemplo; pero tampoco se rompe la relación de la radio con las organizaciones, para el caso, con la asociación de juntas comunales del Chucurí

En Simití, encontré que el grupo de personas que rodea la dirección de la radio comunitaria, entre administradores de empresas, hoteleros, profesores, abogados y psicólogos, es un espacio revitalizado, que por estar entre ser una Junta de Programación y un Comité temático local, piensa en el pueblo y no sólo en la radio, o mejor, piensan la radio para conectar con el pueblo intentando sanarlo de la violencia.

\section{Conclusiones}

El trabajo de estas radios con víctimas no ha sido silenciado por la guerra; al contrario, se ha dinamizado, y el desarrollo tecnológico ha sido un impulsor, como puede verse con el uso complementario de redes sociales, transmisiones on line y la producción de podcast que acercan la radio hablada a la gente.

Las experiencias radiales de construcción de paz de Aredmag, con más de 20 años de historia, siguen vigentes para el post acuerdo de hoy, como los reporteros rurales, una experiencia replicada por la Agencia de Renovación del Territorio- ART- que creó la Red de Reporteros Comunitarios, con radialistas de al menos 20 municipios del país, para que las comunidades sean las voceras 
y contadores de historias de cara a los Planes de Desarrollo con Enfoque Territorial -PDET- un proceso que va a reflejar la visión colectiva de los actores sociales presentes en los territorios, y en el que la participación activa de las comunidades es fundamental.

El salvavidas para no hundirse en el terror de la guerra es construir un tejido comunicativo entre los medios comunitarios, la comunidad, las organizaciones socialesy las instituciones. En la actualidad, la Comisión dela Verdad, una entidad del estado que busca el esclarecimiento de los patrones y causas explicativas del conflicto armado interno que satisfaga el derecho de las víctimas y de la sociedad a la verdad, desarrolla el programa \#LaVerdadEnVozAlta, por el que se llevan a la radio comercial, las historias de vida de las víctimas de la guerra. Se trata de una propuesta liderada por Francisco de Roux, actual presidente de la Comisión de la Verdad y quien liderara en los años 9o los PDP, que como vimos en el caso del Magdalena medio, fueron muy importantes en la consolidación radial y política de Aredmag.

Sin embargo, la labor de consolidar la paz sigue siendo una responsabilidad principalmente de las radios comunitarias, por su conexión con los territorios y su capacidad de crear espacios de encuentro y diálogo intercomunitario, que desde una perspectiva dialógica y sociocultural, constituyen las bases para la reconciliación y la sanación.

Pero en esa lógica, el reto sigue siendo trasladar el diálogo social a la cabina, hacer de los espacios radiales otros espacios sociales para la deliberación, unas radios habladas como apuestas pedagógicas por la paz, que respaldadas por la tecnología, podrían propiciar acercamientos incluso con exilados y otras víctimas desplazadas de sus territorios, que no han podido regresar.

\section{Referencias bibliográficas}

Archila, M., García, M. C., Parra, L., \& Restrepo, A. M. (2013). Luchas sociales en Colombia, en Revistes Cientifiques de la Universitat de Barcelona. Anuari del Conflicte Social, $\mathrm{n}^{\circ} 3$, pp. 533-611. Recuperado de: https://revistes.ub.edu/index.php/ACS/issue/view/957/showToc

Cadavid, A. (2011) La comunicación para el desarrollo en Colombia, los últimos 20 años. Comunicación, desarrollo y cambio social. Interrelación entre comunicación, medios ciudadanos y medios. Bogotá: Editorial Pontificia Universidad Javeriana, 57-83

Centro Nacional De Memoria Histórica. (2013) ¡Basta Ya! Colombia: Memorias de Guerra y Dignidad. Bogotá: Imprenta Nacional.

Durán, O. (2011): “Los colectivos de comunicación ciudadana en el Magdalena Medio, ¿una apuesta de participación social hacia la democratización de los medios?” En: J.M. Pereira y A. Cadavid-Bringe (Eds). Comunicación, desarrollo y cambio social: interrelaciones entre comunicación, movimientos ciudadanos y medios. Bogota : Pontificia Universidad Javeriana, UniMinuto de Dios, UNESCO.

El'Gazi, J. (2011): La experiencia de las emisoras ciudadanas y comunitarias, o cómo hablar de cara al futuro más allá de un conflicto armado. En: J.M. Pereira y A. Cadavid-Bringe (Eds), Comunicación, desarrollo y cambio social: interrelaciones entre comunicación, 
movimientos ciudadanos y medios. Bogota : Pontificia Universidad Javeriana, UniMinuto de Dios, UNESCO.

Fajardo, M.; B. Toloza; F Tibaduiza y O. Marín. (2010) La radio comunitaria. Una empresa social sustentable. San Gil: Resander y UniSanGil,

Fedecacao. (2016). Derecho de petición. Información Fedecacao. En: Ávila Baquero, N. Análisis del efecto de la política de desarrollo rural en la organización del campesinado cacaotero en la subregión de los Yariguíes, Santander (2010-2014) (Disertación doctoral, Universidad del Rosario). Recuperado de https://repository.urosario.edu.co/handle/10336/13129

Ferro M., G. (2013). El río Magdalena. Territorio y cultura en movimiento. En: Boletín cultural y bibliográfico. Volumen XLVIII. N. ${ }^{\circ}$ 84. Bogotá: Banco de la República.

Galvis-Aponte, L. A., Quintero-Fragozo, C. A., (2017). Geografía económica de los municipios ribereños del Magdalena. Documentos de Trabajo Sobre Economía Regional y Urbana; No. 265. Recuperado de http://repositorio.banrep.gov.co/handle/20.500.12134/6980

Gamboa M., J. A. (2013). La expedición de Gonzalo Jiménez de Quesada por el río Magdalena y el origen del Nuevo Reino de Granada (1536-1537). En: Revista Credencial, Historia, No. 283, 130 Bogotá. Recuperado de: http://www.banrepcultural.org/blaavirtual/revistas/ credencial/julio-2013/quesada-rio-magdalena

García A. y D. Orrego (2017) Caracterización de radios comunitarias y públicas en los espacios territoriales de capacitación y reincorporación del proceso de paz. (Documento de Archivo inédito)

Granada, S., Restrepo, J., \& Sánchez, C. (2014). Comunicar En Medio Del Conflicto: El Asesinato de Eduardo Estrada Y El Silenciamiento de La Comunicación Comunitaria Y Del Periodismo Regional En Colombia. Bogotá: Centro Nacional de Memoria histórica y la Universidad Tecnóloga de Bolívar.

González, A. y Rodríguez, C. (2006). Alas para tu voz. Ejercicios de ciudadanía desde una emisora comunitaria. En: Rodríguez, C. (Ed.) Lo que le vamos quitando a la guerra. Bogotá: Centro de Competencia en Comunicación para América Latina. Recuperado de http:// www.c3fes.net/docs/andaqui.pdf

Kanchan K. M. (2015) Our Media, Our Principles, Journalism Studies, 16:5, 750-764, DOI: 10.1080/1461670X.2015.1054195

Kaplún, G. (2007) La Comunicación Comunitaria. Anuario de Medios (pp. 311-320), Recuperado de: https://ng.cl/hd5v

Mesa Nacional Cacaotera. (21 de Febrero de 2013). Cacaoteros santandereanos se suman al paro agrario del 25 de febrero de 2013. Recuperado de: http://prensarural.org/spip/ spip.php?article10285

MinCultura (2010) Voces y sonoridades de un proceso ciudadano. Sistematización del Programa Radios Ciudadanas: espacios para la democracia. Bogota: Presidencia de la República.

O'Brien, A. (2018) (Not) getting the credit: women, liminal subjectivity and resisting neoliberalism in documentary production. Media, Culture \& Society, Vol 40, Issue 5, pp. $673-688$ https://doi.org/10.1177/01634437177344.05

Rodríguez, C., Cadavid, A., \& Durán, O. (2008). De la violencia al discurso. Rodríguez, Clemencia (editora). Lo que le vamos quitando a la guerra. (pp. 141-167) Bogotá: Centro de Competencia en Comunicación para América Latina, Friedrich Ebert Stiftung.

UNODC. "World Drug Report, 2014." June 2014. Page 1, Recuperado de: http://www.unodc. org/documents/wdr2014/World Drug Report 2014. web.pdf 
TAPIAS

Wolfsfeld G (2004) Media and the Path to Peace. Cambridge: Cambridge University Press. Vega, J., C Pérez y C. Tapias (2019). "Radio comunitaria y construcción de paz en Colombia. Comunicación, interacción y planeación participativa para el posconflicto". Revista Latina de Comunicación Social, 74, pp. 1391 a 1410. http://www.revistalatinacs.org/o 74paper/139o/73es.html DOI: $10.4185 /$ RLCS-2019-1390 